\title{
Lifelong Bilingualism Maintains Neural Efficiency for Cognitive Control in Aging
}

\author{
Brian T. Gold, ${ }^{1,2,3}$ Chobok Kim, ${ }^{1,6}$ Nathan F. Johnson, ${ }^{1}$ Richard J. Kryscio, ${ }^{3,4}$ and Charles D. Smith ${ }^{1,2,3,5}$ \\ ${ }^{1}$ Department of Anatomy and Neurobiology, ${ }^{2}$ Magnetic Resonance Imaging and Spectroscopy Center, ${ }^{3}$ Sanders-Brown Center on Aging, ${ }^{4}$ Department of \\ Statistics, and ${ }^{5}$ Department of Neurology, University of Kentucky, Lexington, Kentucky 40536, and ${ }^{\circ}$ Department of Psychology, Kyungpook National \\ University, Daegu, 702-701 South Korea
}

Recent behavioral data have shown that lifelong bilingualism can maintain youthful cognitive control abilities in aging. Here, we provide the first direct evidence of a neural basis for the bilingual cognitive control boost in aging. Two experiments were conducted, using a perceptual task-switching paradigm, including a total of 110 participants. In Experiment 1, older adult bilinguals showed better perceptual switching performance than their monolingual peers. In Experiment 2, younger and older adult monolinguals and bilinguals completed the same perceptual task-switching experiment while functional magnetic resonance imaging (fMRI) was performed. Typical age-related performance reductions and fMRI activation increases were observed. However, like younger adults, bilingual older adults outperformed their monolingual peers while displaying decreased activation in left lateral frontal cortex and cingulate cortex. Critically, this attenuation of age-related over-recruitment associated with bilingualism was directly correlated with better task-switching performance. In addition, the lower blood oxygenation level-dependent response in frontal regions accounted for $82 \%$ of the variance in the bilingual task-switching reaction time advantage. These results suggest that lifelong bilingualism offsets age-related declines in the neural efficiency for cognitive control processes.

\section{Introduction}

Cognitive control refers to the ability to flexibly shape thoughts and behavior to meet internal goals in the face of constantly changing environmental demands (Miller and Cohen, 2001). This kind of cognitive flexibility is critical for successful navigation of the demands of everyday life, yet it declines significantly with age (West, 1996; Kramer et al., 1999). However, new evidence suggests that lifelong bilingualism, or speaking two languages on a daily basis since childhood, can attenuate age-related declines in cognitive control processes (Bialystok and Craik, 2010), and may even delay the onset of dementia symptoms (Bialystok et al., 2007). Current cognitive models suggest that the basis of this boost relates to the bilingual experience of constantly switching between languages, which serves to strengthen task switching and related executive control processes (Green, 1998; Bialystok and Craik, 2010).

These models are based upon findings from psycholinguistic research demonstrating that lifelong bilinguals simultaneously activate both languages during the use of either language (Smith, 1997; Francis, 1999). The simultaneous activation of codes from

Received Aug. 11, 2012; revised 0ct. 10, 2012; accepted 0ct. 14, 2012.

Author contributions: B.T.G. designed research; B.T.G., C.K., and N.F.J. performed research; B.T.G., C.K., and R.J.K. analyzed data; B.T.G. and C.D.S. wrote the paper.

This study was supported by National Institutes of Health Grant AG033036 and National Science Foundation Grant BCS 0814302. We thank Dr. Yaakov Stern and two anonymous reviewers for helpful comments on an earlier version of this manuscript. In addition, we thank Sara Cilles for her assistance in recruiting, and testing participants. The authors declare no competing financial interests.

Correspondence should be addressed to Brian T. Gold, Department of Anatomy and Neurobiology, University of Kentucky College of Medicine, Lexington, KY 40536-0298. E-mail: brian.gold@uky.edu.

DOI:10.1523/JNEUROSCI.3837-12.2013

Copyright $\odot 2013$ the authors $\quad 0270-6474 / 13 / 330387-10 \$ 15.00 / 0$ different languages requires that lifelong bilinguals inhibit intrusion from the context inappropriate language. In particular, lifelong bilinguals must continuously monitor context to determine when language switches are appropriate and inhibit the language not currently under use (Green, 1998; Bialystok and Craik, 2010). Importantly, previous work has reported bilingual cognitive control advantages even for nonlinguistic perceptual tasks, suggesting that lifelong bilingualism may strengthen general-purpose executive control systems (Costa et al., 2008; Bialystok and Craik, 2010).

However, the functional neuroanatomic bases of bilingual cognitive control advantages in aging remain unknown. Here we explore this issue using functional magnetic resonance imaging (fMRI) and a perceptual task-switching paradigm. When participants are required to switch between two tasks there is an increase in reaction time (RT), termed a switch cost, compared with performing either task in isolation. Functional neuroimaging studies have demonstrated that young adults recruit a distributed network of frontoparietal regions when switching between tasks (Dove et al., 2000; Brass and von Cramon, 2002; Reynolds et al., 2004; Kim et al., 2011, 2012). Compared with younger adults, older adults tend to show larger RT switch costs and brain activation increases in task-related frontoparietal regions (i.e., decreased neural efficiency), and/or recruitment of additional regions (i.e., neural compensation) (DiGirolamo et al., 2001; Gold et al., 2010; Jimura and Braver, 2010; Madden et al., 2010).

The cognitive control advantage conferred by lifelong bilingualism in aging may be associated with improved neural efficiency and/or successful neural compensation. The goal of Experiment 1 was to determine whether bilingual older adults 
Table 1. Group means, SDs (in parentheses), and p values for demographic and neuropsychological scores for Experiment 2

\begin{tabular}{|c|c|c|c|c|c|c|c|}
\hline & Younger & & Older & & $p$ Values & & \\
\hline & Monolingual & Bilingual & Monolingual & Bilingual & Age group & Language group & Age $\times$ language \\
\hline Age & $32.2(3.3)$ & $31.6(4.3)$ & $64.4(5.1)$ & $63.9(4.0)$ & $<0.001$ & 0.92 & 0.74 \\
\hline Education & $17.1(2.6)$ & $18.3(2.5)$ & $17.5(2.6)$ & $17.4(2.2)$ & 0.37 & 0.38 & 0.23 \\
\hline ISP & $26.1(5.3)$ & $21.7(10.1)$ & $21.6(7.0)$ & $19.7(8.7)$ & 0.12 & 0.19 & 0.58 \\
\hline PPVT & $107.2(11.8)$ & $101(10.7)$ & $110.1(13.9)$ & $105.3(18.5)$ & 0.28 & 0.13 & 0.85 \\
\hline IQ & $126.6(23.3)$ & $121.3(15.6)$ & $124.6(20.2)$ & $127.6(22.5)$ & 0.64 & 0.80 & 0.38 \\
\hline DF & $10.7(2.5)$ & $10.8(2.4)$ & $10.6(2.0)$ & $9.7(2.1)$ & 0.22 & 0.50 & 0.38 \\
\hline DB & $10.4(2.8)$ & $10.3(3.1)$ & $10.5(2.1)$ & $10.5(3.2)$ & 0.83 & 0.96 & 0.93 \\
\hline
\end{tabular}

DB, Digits backward; DF, digits forward; IQ, Cattell Culture Fair Intelligence Test; ISP, Index of Social Position; PPVT, Peabody Picture Vocabulary Test. Values for the PPVT, IQ, and DB are age-scaled scores.

show a behavioral advantage over their monolingual peers in perceptual task switching. The goals of Experiment 2 were to (1) replicate the bilingual advantage using different subject groups and (2) identify functional neuroanatomic variations in bilingual task switching that are directly linked with their behavioral advantages. To understand bilingual advantages in the context of aging, Experiment 2 included four participant groups: younger adult and older adult groups that were either monolingual or lifelong bilingual.

\section{Materials and Methods}

\section{Experiment 1: Participants}

There were a total of 30 right-handed community dwelling participants, divided equally between two groups: 15 older adult monolinguals ( 8 females), with a mean age of 63.3 years $(\mathrm{SD}=3.8)$, and 15 older adult bilinguals ( 8 females) with a mean age of 64.1 years $(S D=4.4)$. Exclusionary criteria were color blindness, a major head injury and/or concussion, stroke, and a neurological or psychiatric disorder.

Experiment 2: Participants

There were a total of 80 right-handed community dwelling participants (Table 1), divided equally between four groups: 20 younger adult monolinguals ( 12 females), 20 younger adult bilinguals ( 13 females), 20 older adult monolinguals (10 females), and 20 older adult bilinguals (10 females). Exclusionary criteria included those used in Experiment 1. Additional exclusionary criteria for this fMRI experiment were claustrophobia, high blood pressure, hypercholesterolemia, diabetes, heart disease, the use of medications that affect the brain, and the presence of metal fragments and/or metallic implants contraindicated for MRI. A senior neurologist (C.D.S.) reviewed the T1-weighted images for cortical atrophy and ventricular size. All participants were found to be within normal age-related limits.

\section{Procedures common to Experiments 1 and 2}

Informed consent was obtained from each participant under an approved University of Kentucky Institutional Review Board protocol. Language status was determined via a detailed questionnaire about language history similar to that used in previous research in this area (Bialystok et al., 2006). The questionnaire included questions about age and place of language acquisition and proficiency of each language compared with a native speaker. Strict criteria concerning language background were applied for classification in the study as a lifelong bilingual or monolingual. Lifelong bilinguals had to have been speaking English and another language on a daily basis since the age of 10 years old or younger. Lifelong bilinguals had to rate themselves as completely proficient in their two languages and comparable in proficiency to monolingual speakers of each language (English proficiency was also assessed objectively as described below). Lifelong bilinguals spoke English and a variety of second languages, whereas lifelong monolinguals spoke only English, and had no significant exposure to a second language (language background of participants in Experiment 2 are presented in Table 2).

\section{Cognitive and demographic measures}

The Peabody Picture Vocabulary Test. This is a culture-fair measure used to assess proficiency in English (Dunn and Dunn, 1997). There are a total of 204 test items. Test items are presented on pages containing four
Table 2. Language background of monolingual and bilingual subjects from Experiment 2

\begin{tabular}{lll}
\hline & Monolingual & Bilingual \\
\hline $\begin{array}{c}\text { Younger } \\
\text { Languages spoken }\end{array}$ & English & $\begin{array}{c}\text { English + African language (Luo, Swahili), French, } \\
\text { German, Indian language (Gujarati, Hindi), } \\
\text { Greek, Spanish, Turkish, Mandarin }\end{array}$ \\
$\begin{array}{c}\text { Percentage born } \\
\text { in United States }\end{array}$ & $95 \%$ & $25 \%$ \\
$\begin{array}{c}\text { Older } \\
\text { Languages spoken }\end{array}$ & English & $\begin{array}{c}\text { English + African language (Igbo, Swahili), Fili- } \\
\text { pino, French, German, Indian language (Guja- } \\
\text { rati, Hindi, Konkani), Spanish }\end{array}$ \\
$\begin{array}{c}\text { Percentage born } \\
\text { in United States }\end{array}$ & $85 \%$ & $25 \%$ \\
\hline
\end{tabular}

black-and-white pictures. Participants were read a word and were asked to choose the picture on that page that best corresponds to the word.

The Hollingshead Two-Factor Index of Social Position. The Hollingshead Two-Factor Index of Social Position (ISP) was used as a measure of socioeconomic states (SES) (Hollingshead, 1958). The ISP is based on an individual's occupation and highest level of formal education. It is calculated by assigning numeric values, from 1 to 7 , to an individual's occupation and education. Scores are then weighted by multiplying by 7 (occupation) and 4 (education). Values are then summed to produce a social index. Lower values represent higher earning occupations and more years of education.

The Cattell Culture Fair Intelligence Test. The Cattell Culture Fair (CCF) Intelligence Test (Cattell and Cattell, 1960) is a test of fluid intelligence that is not influenced by cultural background or verbal ability. The CCF (Scale 3) consists of 50 items and assesses inductive reasoning about relationships in shapes and figures.

The Digits Span Subtests of the Wechsler Memory Scale. In the Digits Span Subtests of the Wechsler Memory Scale (Wechsler, 1997) participants were read digit lists aloud and were instructed to repeat each set of digits verbally in the same order (digit forward; DF) and in reverse order (digit backward; DB). In both conditions participants received two trials. Standard termination procedures were followed and the totals for the DF and $\mathrm{DB}$ sets were based on the number of trials that were accurately reported in the correct order.

\section{Task procedure}

Subjects completed a color-shape task-switching paradigm. The stimuli consisted of two possible shapes (circle or square), in one of two possible colors (red or blue), presented in the center of the screen. Previous research has shown that age-related declines are larger for global switch costs than local switch costs (Kray and Lindenberger, 2000; Meiran et al., 2001). Thus, in the present experiments, a blocked design (Fig. 1) that focused on global switch costs (the average performance difference between the switch task and single task conditions) was used to maximize power to find potential effects of age and age by language group interactions.

The trial and block design structures were selected based on behavioral pilot studies and results from our previous task-switching study of aging, 


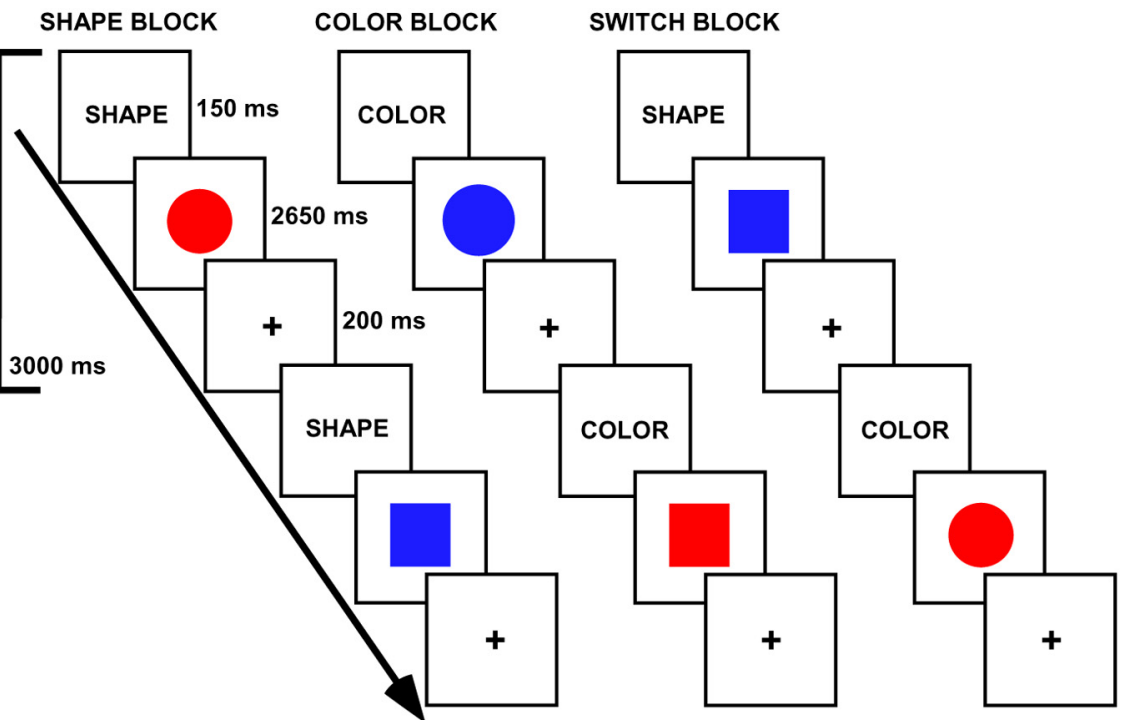

Figure 1. Task-switching paradigm. Tasks were indicated via cue words. In shape blocks, participants decided if a stimulus was a circle or square. In color blocks, participants decided if a stimulus was red or blue. In switch blocks, participants alternated between shape and color decisions.

in which robust switch effects were observed for both younger and older adult groups (Gold et al., 2010). The block design included four conditions: shape block, color block, switch (shape/color) block, and baseline fixation block (in which participants focused their vision on a central crosshair $(+)$ ). In the shape task, participants decided if a stimulus was a circle or square. In the color task, participants decided if a stimulus was red or blue. In the switch task, participants were required to alternate between shape and color decisions. Participants indicated their responses via a left or right button press.

Task blocks were $60 \mathrm{~s}$ in duration (20 trials per block), and fixation blocks were $30 \mathrm{~s}$ in duration. There were a total of three runs. Each run contained four task blocks and five fixation blocks. One run consisted of two blocks of each of the color task and shape tasks. The other two runs contained one block each of the color and shape tasks and two switch blocks (in which the color and shape tasks switched pseudorandomly; every second or third trial on average). Thus, there were a total of 80 trials per task condition across the experiment. The order of runs, task blocks within runs, and stimulus-response mappings were counterbalanced across participants. The experiment was programmed via E-Prime v1.2. RTs and accuracies for subject responses on each trial were recorded by the stimulus presentation program.

\section{Experiment 1 procedures}

The RT and accuracy (percentage errors) data were analyzed in the context of mixed ANOVAs, with condition (switch vs nonswitch) as the within-group factor and language group (monolingual vs bilingual) as the between-group factor. Behavioral switch costs were computed by subtracting each subject's mean (RT or percentage of errors) in the nonswitch condition from their mean (RT or percentage of errors) in the switch condition.

\section{Experiment 2 procedures}

Participants completed the same perceptual task-switching paradigm described above during fMRI acquisition. The experiment was backprojected onto a screen placed outside the magnet and viewed by the subjects through a mirror attached to the head coil. Behavioral analyses were similar to those for Experiment 1. However, to control for general age-related slowing, RT switch costs were analyzed using proportional scaling ([switch RT - nonswitch RT]/nonswitch RT × 100).

\section{Imaging acquisition}

Imaging data were acquired on a 3 T Siemens TIM scanner at the Magnetic Resonance Imaging and Spectroscopy Center at University of Kentucky. T2*-weighted functional images were collected using a gradient- echo (EPI) sequence (33 interleaved slices, $\mathrm{TR}=2000 \mathrm{~ms}, \mathrm{TE}=30 \mathrm{~ms}$, flip angle $=77^{\circ}$, FOV $=224 \mathrm{~mm}^{2}$, matrix $=64 \times 64$, isotropic $3.5 \mathrm{~mm}$ voxels). A double-echo gradient-echo sequence $(\mathrm{TE} 1=5.19 \mathrm{~ms}$, TE2 $=7.65 \mathrm{~ms})$ with slice position and spatial resolution matching those of the EPI acquisition was used to map the spatial inhomogeneity of the $\mathrm{B}_{0}$ field. T1weighted structural images were collected using the magnetization-prepared rapid gradient-echo (MPRAGE) sequence $(\mathrm{TR}=$ $2100 \mathrm{~ms}, \mathrm{TE}=2.93 \mathrm{~ms}$, TI $=1100 \mathrm{~ms}, 1 \mathrm{~mm}$ isotropic voxels).

\section{fMRI data analysis}

Statistical Parametric Mapping (SPM8; http://www.fil.ion.ucl.ac.uk/spm) was used for analyses of fMRI data. After discarding the first five functional volumes, sinc interpolation was used to correct slice timing. The timingcorrected images were then realigned to the first volume to correct for head motion. The resulting images were unwarped via $\mathrm{B}_{0}$ field maps to reduce magnetic field distortions. The T1-weighted (MPRAGE) image was then coregistered to the first functional volume using a mutual information algorithm. The coregistered MPRAGE image was then used to determine the nonlinear basis function parameters for transformation into the standard space of the Montreal Neurological Institute (MNI) template (2 $\mathrm{mm}$ isotropic voxels). This transformation was then applied to the functional data, which was re-sliced to $2 \mathrm{~mm}$ isotropic voxels and spatially smoothed with an $8 \mathrm{~mm}$ full-width at half-maximum (FWHM) Gaussian kernel. Finally, highpass filtering (a $128 \mathrm{~s}$ cutoff) was applied to the images to remove low-frequency drifts.

Statistical analyses at the subject-level were conducted such that predictor variables in the design matrix were composed of epochs representing each task block, with the fixation blocks being modeled implicitly. Each epoch was convolved with a canonical hemodynamic response function producing contrasts for single-task (nonswitch), switch-task, and switch versus nonswitch. Contrast images from each participant were then entered into a series of group analyses in the context of a flexible factorial design.

We first tested the hypothesis that bilingual older adults may use common primary "task-switching regions" more efficiently than their monolingual peers. As a first step for this analysis, we identified commonly activated task-switching regions using a conjunction analysis of switch condition versus nonswitch condition across all 80 study participants. The conjunction analysis tested against the conjunction null (Friston et al., 2005), using a statistical threshold corrected at $p<0.05$ level via the false discovery rate. Task-switching signal changes (switch - nonswitch) in each of the seven regions that were commonly activated in the conjunction map were then extracted from each subject for further analysis using MarsBaR (http://marsbar.sourceforge.net). Regions of interest (ROIs) were defined as 3D areas including all contiguous voxels within $10 \mathrm{~mm}$ of peak activations. The task-switching signal magnitude in each ROI was analyzed in the context of a $2 \times 2$ ANOVA with age group (younger vs older adult) and language group (monolingual vs bilingual) as factors. A conservative familywise significance threshold of $p<0.007$ (i.e., $p=0.05 / 7$ ) was applied to each ROI analysis to correct for the seven ROIs being tested.

We next tested the hypothesis that task-switching advantages in older bilinguals may relate to compensatory activations outside the common task-switching network. To maximize power to detect potential group differences, we restricted the search space of this analysis to brain regions not activated in the conjunction map. This was accomplished by exclusive masking out of voxels activated in the conjunction map. Monte Carlo simulations were then run using the AlphaSim program (http://afni.nimh.nih.gov/pub/dist/doc/manual/ 
AlphaSim.pdf) to determine the appropriate combination of significance level and cluster threshold for the specific dimensions of the search space in the resulting masked image. The Monte Carlo simulations used 1000 iterations. A significance threshold of $p<0.005$ and a minimum cluster size of 138 contiguously activated voxels $\left(1104 \mathrm{~mm}^{3}\right)$ were used to achieve a corrected significance level of $p<0.05$.

\section{Relationships between behavioral and} neural switch costs

These analyses were intended to identify the neural correlates of the behavioral switching advantage displayed by bilingual older adults compared with their monolingual peers. Toward that end, neural switch costs were computed in any region showing significantly different activation magnitude between the two older adult groups, in either of the analyses described above. To compute neural switch costs, the average magnitude of signal change at the second and third time points (2-6 s after stimulus onset) was first extracted for each subject, for each condition relative to fixation, to capture the peak of the blood oxygenation level-dependent (BOLD) response within each ROI. Neural switch costs were then computed by subtracting each subject's peak BOLD responses in the nonswitch condition from their peak BOLD responses in the switch condition. Correlations were then run between behavioral switch costs and neural switch costs.

\section{Structural analysis}

Voxel-based morphometry (VBM; http://www.fil.ion.ucl.ac.uk/spm) using SPM8 was undertaken to identify potential differences in gray matter volume between the age-matched bilingual and monolingual groups. Preprocessing of images included segmentation, bias correction, and spatial normalization, incorporated into a single generative model using SPM prior probability templates (Ashburner and Friston, 2005). Gray matter (GM) images were normalized to their own custom templates in MNI space using a set of nonlinear basis functions. A modulation step was also incorporated into the preprocessing model to explore regional differences in absolute volume. Intracranial volume was estimated as the sum of GM, white matter (WM), and CSF volume for each participant (for use as a nuisance covariate in statistical analysis). Normalized, modulated, GM images were smoothed using an $8 \mathrm{~mm}$ FWHM isotropic Gaussian kernel.

The preprocessed GM data were analyzed within the framework of the GLM. Statistical parametric maps of between-group differences in GM volume were determined using a full-factorial model (a two-sample $t$ test) with unequal variance and intracranial volume as a nuisance covariate. Second-level, group linear contrasts were then conducted on parameter estimates from the model. The voxel values for the contrasts constituted an SPM of the $t$ statistic. Differences between groups were assessed using a statistical threshold of $p<0.05$ (familywise error corrected for multiple comparisons).

\section{Results}

\section{Experiment 1}

Both groups were able to perform the switch and nonswitch conditions with high accuracy (both $\geq 92 \%$ correct in each condition). The main effect of condition was significant $\left(F_{(1,14)}=31.1\right.$, $p<0.001)$, with higher accuracy during the nonswitch condition $(M=97.5 \%, \mathrm{SD}=2.2)$ than the switch condition $(M=95.1 \%$, $\mathrm{SD}=3.5)$. There was no main effect of language group, or condition $\times$ language group interaction (both $F s<1$ ).
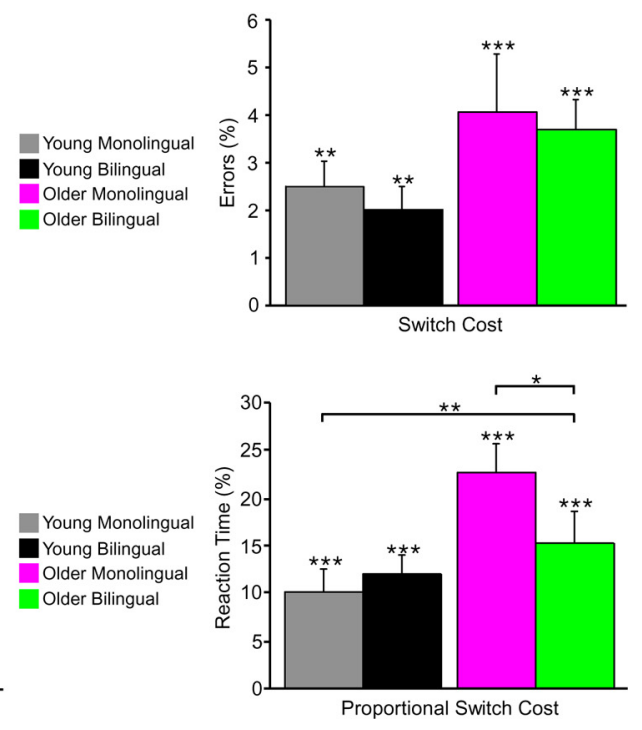

Proportional Switch Cost

Behavioral results from Experiment 2. Mean performance data and switch costs according to age group and language group. For proportional RT switch costs, the long horizontal bar indicates an effect of age group, and the short horizontal bar indicates an age group by language group interaction. ${ }^{*} p=0.056,{ }^{* *} p<0.01,{ }^{* * *} p<0.001$.

For RTs, the main effect of condition was significant $\left(F_{(1,14)}=\right.$ $49.79, p<0.001)$, due to longer RTs for the switch condition $(M=906.1 \mathrm{~ms}, \mathrm{SD}=194.9)$ than the nonswitch condition $(M=$ $778.9 \mathrm{~ms}, \mathrm{SD}=158.1)$. There was no main effect of language group $\left(F_{(1,14)}=0.14, p=0.71\right)$. However, there was a condition $\times$ language group interaction $\left(F_{(1,14)}=15.9, p<0.01\right)$, due to smaller switch costs for bilingual older adults $(M=102.2$ $\mathrm{ms}, \mathrm{SD}=74.8)$ than monolingual older adults $(M=152.1 \mathrm{~ms}$, $\mathrm{SD}=72.9)$.

Importantly, the group differences in task switching were not due to several key demographic or cognitive variables, which have been shown to affect cognitive control processes. Specifically, there were no group differences in sex, age, education level, $S E S$, intelligence, or digit span performance (all $p s \geq 0.62$ ) (for details on these measures, see Materials and Methods, Experiment 1 and 2 procedures).

\section{Experiment 2}

\section{Behavioral data}

Mean error rates, RTs, and behavioral switch costs are presented in Figure 2. Each of the four groups was able to perform the switch and nonswitch conditions with high accuracy (all groups $\geq 93 \%$ correct in each condition). The main effect of condition was significant $\left(F_{(1,76)}=76.23, p<0.001\right)$, with higher accuracy during the nonswitch condition $(M=98.2 \%, \mathrm{SD}=3.4)$ than the switch condition $(M=94.7 \%, \mathrm{SD}=5.6)$. Conversely, there was no effect of age group $\left(F_{(1,76)}=2.11, p=0.15\right)$ or language group $\left(F_{(1,76)}=0.22, p=0.64\right)$, and none of the interactions were significant (all $p s \geq 0.25$ ).

For RTs, the main effect of condition was significant $\left(F_{(1,76)}=\right.$ 148.37, $p<0.001)$, due to longer RTs for the switch condition $(M=880.8 \mathrm{~ms}, \mathrm{SD}=202.8)$ than the nonswitch condition $(M=$ $767.4 \mathrm{~ms}, \mathrm{SD}=161.4)$. The main effect of age group was also significant $\left(F_{(1,76)}=12.74, p<0.001\right)$, due to older adults having longer RTs $(M=890.8 \mathrm{~ms}, \mathrm{SD}=194.4)$ than younger adults $(M=757.4 \mathrm{~ms}, \mathrm{SD}=164.0)$. However, there was no main effect of language group $\left(F_{(1,76)}=0.31, p=0.58\right)$.

Analyses of RT switch costs were conducted on proportional costs ([switch RT - nonswitch RT]/nonswitch RT × 100) to 

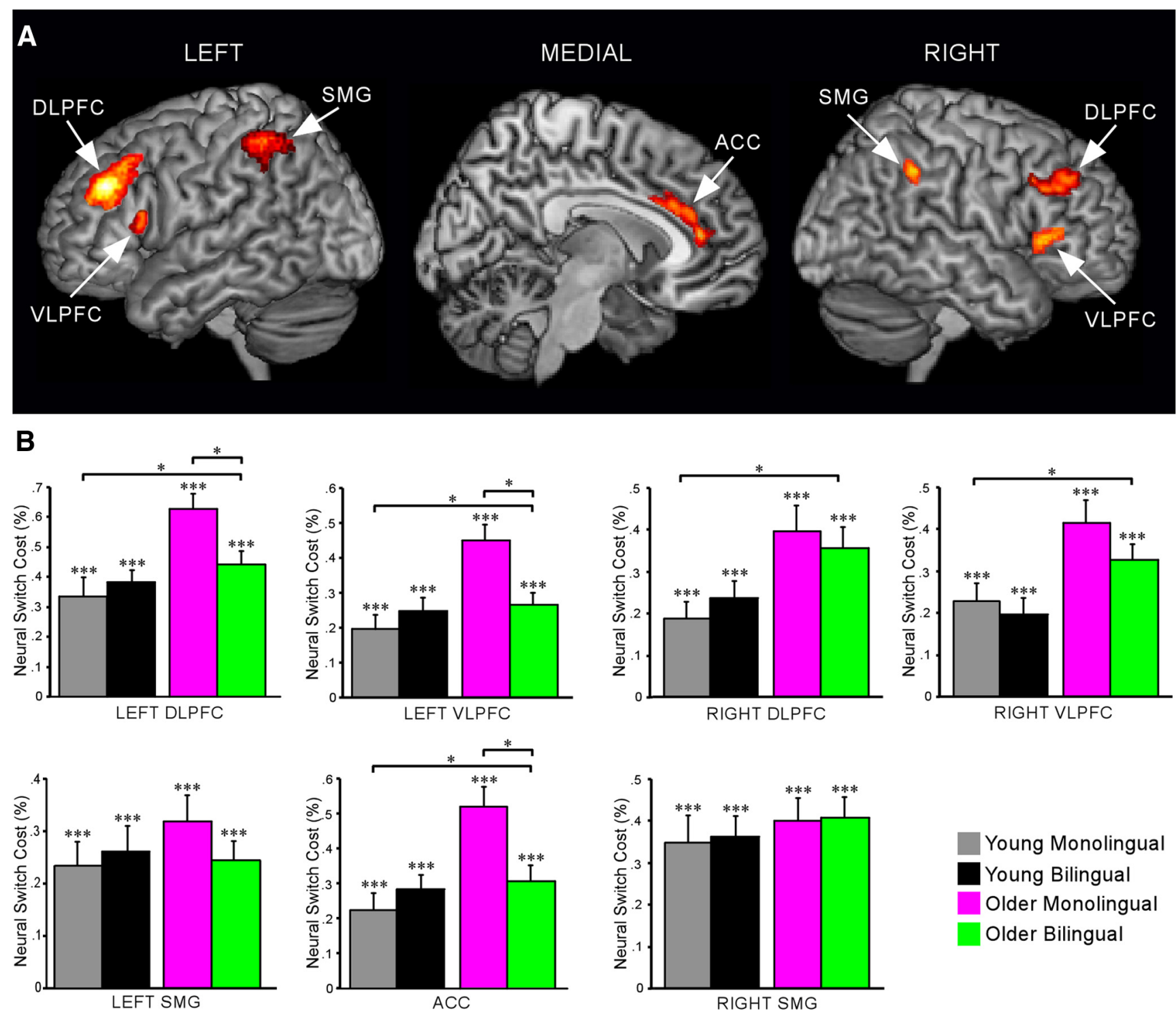

Figure 3. fMRI results. $\boldsymbol{A}$, Voxelwise conjunction activation map of the switch-nonswitch contrast across groups. $\boldsymbol{B}$, Mean BOLD switch costs for each group in each of the seven ROls identified in the conjunction results. The long horizontal bars indicate effects of age group, and the short horizontal bars indicate age by language interactions. ${ }^{*} p<0.007,{ }^{* *} p<0.001$.

control for general age-related slowing. The main effect of age group on proportional RT switch costs was significant $\left(F_{(1,76)}=\right.$ $8.32, p<0.01)$, due to larger RT costs for older adults $(M=$ $18.6 \%, \mathrm{SD}=14.9)$ than younger adults $(M=11.1 \%, \mathrm{SD}=7.8)$. The main effect of language group was not significant $\left(F_{(1,76)}=\right.$ $1.76, p=0.19)$. Of central relevance, there was an age group $\times$ language group interaction $\left(F_{(1,76)}=4.5, p<0.05\right)$. Planned post hoc comparisons indicated a marginally significant difference between the older adult groups $\left(t_{(38)}=1.97, p=0.056\right)$, due to smaller proportional RT switch costs of older bilinguals $(M=$ $14.1 \%, \mathrm{SD}=13.2)$ than older monolinguals $(M=23.0 \%$, $\mathrm{SD}=15.5)$. In contrast, there was no difference between the proportional RT switch costs of younger bilinguals $(M=12.1 \%$, $\mathrm{SD}=6.3)$ and younger monolinguals $(M=10.0 \%, \mathrm{SD}=9.2)$ $\left(t_{(38)}=0.83, p=0.41\right)$.

As in Experiment 1, the group differences in task switching were not due to several key demographic or cognitive variables that have been shown to affect cognitive control processes. Specifically, sex distribution was not different between any of the groups (all $p s \geq 0.75$ ), and there were no group differences or age group $\times$ language group interactions in education level, SES, intelligence, or digit span performance (see Materials and Methods, Experiment 1 and 2 procedures for details on these measures and Table 1 for results).

\section{fMRI data}

Results from the conjunction analysis of the switch condition versus the nonswitch condition across all subjects are shown in Figure $3 A$ and listed in Table 3. Compared with the nonswitch condition, the switch condition resulted in prominent activation of bilateral dorsolateral prefrontal cortex (DLPFC; BA 46/9), bilateral ventrolateral prefrontal cortex (VLPFC; BA 44/45), anterior cingulate cortex (ACC; BA 24/32), and bilateral supramarginal gyrus (SMG; BA 40).

Group differences within task-switching regions. Taskswitching signal changes in these seven ROIs were extracted to test whether neural switch cost magnitudes in these commonly activated ROIs were affected by age group, language group, or their interaction (Fig. 3B). These data were analyzed in the context of $2 \times 2$ ANOVAs. The results of these ANOVAs are sum- 
Table 3. Task-switching activation coordinates in the primary common network

\begin{tabular}{lrrrll}
\hline Region & \multicolumn{1}{c}{$Y$} & $Y$ & $Z$ & BA & $Z$-score \\
\hline Left DLPFC & -46 & 26 & 28 & $46 / 9$ & 5.82 \\
Right DLPFC & 44 & 24 & 26 & $46 / 9$ & 4.84 \\
Left VLPFC & -48 & 22 & 6 & $44 / 45$ & 4.62 \\
Right VLPFC & 45 & 20 & 0 & $45 / 47$ & 5.23 \\
ACC & -2 & 38 & 12 & $24 / 32$ & 5.22 \\
Left SMG & -40 & -60 & 42 & 40 & 4.44 \\
Right SMG & 42 & -56 & 38 & 40 & 4.64
\end{tabular}

ACC, Anterior cingulate cortex; BA, Brodmann area; DLPFC, dorsolateral prefrontal cortex; SMG, supramarginal gyrus; VLPFC, ventrolateral prefrontal cortex.

marized in Table 4 . There were main effects of age group in each of the five frontal ROIs (all $p$ s $<0.007$; familywise significance threshold). As can be seen in Table 4, the effects of age group were due to older adults having increased activation compared with younger adults in each of these five ROIs. In contrast, there were no main effects of language group in any of the seven ROIs.

Of central relevance, three of the five frontal ROIs showing main effects of age group also showed age group $\times$ language group interactions (left DLPFC, left VLPFC, and ACC). Planned post hoc comparisons indicated that older adult bilinguals had lower switch costs than older adult monolinguals in each of these three regions (left DLPFC: $t_{(38)}=3.47, p<0.007$; left VLPFC: $t_{(38)}=3.39 p<0.007$; ACC: $\left.t_{(38)}=3.51, p<0.007\right)$. In contrast, there were no switch cost differences between the younger adult bilinguals and younger adult monolinguals in any of these regions (left DLPFC: $t_{(38)}=0.95, p=0.35$; left VLPFC: $t_{(38)}=1.11$, $p=0.27$; ACC: $\left.t_{(38)}=1.52, p=0.17\right)$. In addition, no age group $\times$ language group interactions or differences between agematched language groups in switch costs were observed in the right DLPFC, right VLPFC, or SMG regions.

Relationship between behavioral and neural switch costs. Regression analyses were conducted with neural switch costs in each of the three ROIs showing magnitude differences between the older adult groups (left DLPFC, left VLPFC, and ACC) as the independent variable and behavioral switch cost as the dependent variable (Fig. 4). Error switch costs were positively correlated with neural switch costs in the ACC in monolingual older adults $\left(r_{(20)}=0.47, p<0.05\right)$, and there was a trend toward a positive correlation in bilingual older adults $\left(r_{(20)}=0.39, p=0.08\right)$. In contrast, error switch costs were not correlated with neural switch costs in either the left DLPFC or left VLPFC, in either monolingual or bilingual older adults (all $p s \geq 0.29$ ).

Proportional RT switch costs were positively correlated with neural switch costs in the left DLPFC in both bilingual older adults $\left(r_{(20)}=0.44, p<0.05\right)$ and monolingual older adults $\left(r_{(20)}=0.48, p<0.05\right)$, with neural switch costs in the left VLPFC in bilingual older adults $\left(r_{(20)}=0.44, p<0.05\right)$ and marginally in monolingual older adults $\left(r_{(20)}=0.39, p=0.07\right)$, and with neural switch costs in the ACC in both bilingual older adults $\left(r_{(20)}=0.46, p<0.05\right)$ and monolingual older adults $\left(r_{(20)}=0.52, p<0.05\right)$.

Mediation analysis. The above results identified three regions showing (1) significantly higher task-switching BOLD response in older adult monolinguals than bilinguals and (2) a positive correlation between BOLD magnitude and proportional RT switch costs in both older adult groups. Together, these findings raised the possibility that neural response (indirectly reflected by BOLD magnitude) in these task-switching regions may mediate differences in RT switch costs between the two older adult groups. Hierarchical regression analyses predicting switch cost RT were conducted to explore this possibility (Table 5).
There was no difference in the variance accounted for in predicting RT switch costs in a model including each of the three ROIs from a model using mean signal change across those ROIs $(F<1)$. Thus, mean BOLD signal change across the three ROIs was used. In model 1, when language group was the only predictor, it was a marginally significant predictor of switch cost RT, accounting for $9.2 \%$ of the variance. In model 2 , when mean BOLD signal across the three ROIs was entered first, followed by language group, BOLD signal was a significant predictor, accounting for $37.7 \%$ of the variance in RT switch costs. After controlling for BOLD magnitude in these ROIs, language group was no longer a significant predictor of switch cost RT (accounting for only $1.7 \%$ of the variance).

To assess the degree to which BOLD magnitude in the three ROIs attenuated the amount of variance in switch cost RT that can be explained by language group, we followed a previously suggested procedure (Salthouse, 1993), in which we subtracted the amount of variance in switch cost RT uniquely associated with language group (when BOLD magnitude was included in the model) from the amount of variance in switch cost RT associated with language group as a sole predictor. We then divided this difference by the amount of language grouprelated variance in switch cost $\mathrm{RT}$ when language group was the sole predictor. Results indicated that BOLD magnitude in the three ROIs attenuated $82 \%$ of the language group-related variance in switch cost RT.

Group difference outside task-switching regions. We next explored the possibility of group differences in neural switch cost activation outside the primary common task-switching network (outside the ROIs identified in the conjunction analysis). Results indicated an effect of language group in a single region: the left middle temporal gyrus (MTG). In contrast, there were no main effects of age group or age by language interactions surviving multiple comparisons correction. Direct post hoc comparisons indicated that left MTG activation was higher in each of the bilingual groups compared with their age-matched monolingual groups. Subsequent correlation analyses indicated that magnitude of activation in the left MTG was not correlated with behavioral performance in either of the older adult groups (Fig. 5) or younger adult groups (data not shown). There were no other activation differences between the age-matched bilingual and monolingual groups in either direction, even at a very liberal uncorrected significance level of $p<0.01$.

\section{VBM data}

There were no differences in GM volume between either of the age-matched bilingual and monolingual groups in either direction. Even when a very liberal uncorrected significance level of $p<0.01$ was used, no group differences between either of the age-matched bilingual and monolingual groups were observed.

\section{Discussion}

Our results provide the first direct evidence of a neural basis for bilingual cognitive control advantages in aging. Our bilingual and monolingual groups were matched on relevant demographic and neuropsychological scores that have been linked with cognitive control performance including education level, SES, and IQ. In addition, bilingual participants did not score higher than their monolingual peers on tests of simple working memory span. Nevertheless, across two experiments using different subjects, older adult bilinguals switched between perceptual tasks significantly faster than their monolingual peers. Experiment 2 revealed that older adult bilinguals showed a pattern of fMRI results similar to the 
Table 4. Task-switching activation means, SDs (in parentheses), and $p$ values for primary common regions

\begin{tabular}{|c|c|c|c|c|c|c|c|}
\hline & \multicolumn{2}{|l|}{ Younger } & \multicolumn{2}{|l|}{ Older } & \multicolumn{3}{|l|}{$p$ values } \\
\hline & Monolingual & Bilingual & Monolingual & Bilingual & Age group & Language group & Age $\times$ language \\
\hline Left DLPFC & $0.33(0.29)$ & $0.38(0.15)$ & $0.64(0.24)$ & $0.44(0.16)$ & $<0.007$ & 0.12 & $<0.007$ \\
\hline Left VLPFC & $0.19(0.18)$ & $0.24(0.12)$ & $0.45(0.19)$ & $0.26(0.14)$ & $<0.007$ & 0.09 & $<0.007$ \\
\hline Right DLPFC & $0.18(0.14)$ & $0.25(0.17)$ & $0.39(0.20)$ & $0.36(0.12)$ & $<0.007$ & 0.84 & 0.17 \\
\hline Right VLPFC & $0.23(0.17)$ & $0.20(0.15)$ & $0.41(0.18)$ & $0.32(0.14)$ & $<0.007$ & 0.10 & 0.48 \\
\hline $\mathrm{ACC}$ & $0.22(0.22)$ & $0.28(0.20)$ & $0.53(0.23)$ & $0.31(0.19)$ & $<0.007$ & 0.08 & $<0.007$ \\
\hline Left SMG & $0.23(0.20)$ & $0.26(0.22)$ & $0.32(0.21)$ & $0.25(0.18)$ & 0.46 & 0.61 & 0.24 \\
\hline Right SMG & $0.35(0.18)$ & $0.37(0.24)$ & $0.39(0.24)$ & $0.40(0.16)$ & 0.45 & 0.72 & 0.76 \\
\hline
\end{tabular}

L, Left; R, right; ACC, anterior cingulate cortex; DLPFC, dorsolateral prefrontal cortex; SMG, supramarginal gyrus; VLPFC, ventrolateral prefrontal cortex.
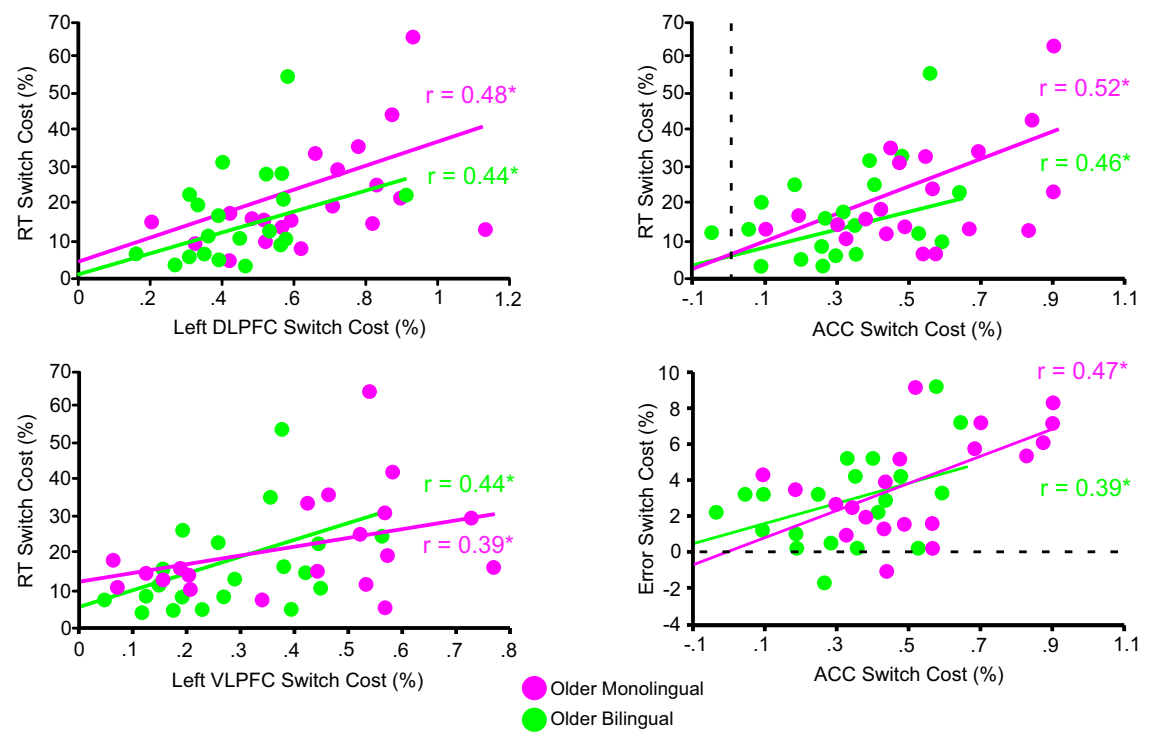

Figure 4. Relationship between neural and behavioral switch costs in older adults. Regression plots show the significant correlations between neural switch costs and proportional RT switch costs or error switch costs in the three regions showing age by language group interactions in Figure 3B. Each circle represents one of the 20 participants in each older adult (monolingual or bilingual) group.

Table 5. Effects of bilingualism and BOLD signal on proportional RT switch costs

\begin{tabular}{|c|c|c|c|c|}
\hline & $r^{2}$ & Increment in $r^{2}$ & $F$ & $\%$ Attenuation \\
\hline \multicolumn{5}{|l|}{ Model 1} \\
\hline Language & 0.092 & & $3.86^{*}$ & \\
\hline \multicolumn{5}{|l|}{ Model 2} \\
\hline BOLD & 0.377 & & $7.54^{* * *}$ & \\
\hline Language & 0.394 & 0.017 & 0.46 & 81.52 \\
\hline
\end{tabular}

younger adult groups: they outperformed monolingual older adults while requiring less activation in several frontal brain regions linked with effortful processing. The details of these findings and their implications concerning the potential neuroprotective effects of bilingualism on cognitive control processes are discussed below.

Behavioral results demonstrated that language group interacted with age group such that bilingual older adults were significantly faster than their monolingual peers at switching between perceptual tasks. These findings are consistent with previous behavioral results of larger inhibitory control advantages associated with lifelong bilingualism in older adults than younger adults (Bialystok et al., 2006). In young adults, who are in their so-called "cognitive prime years," the effects of bilingualism on cognitive control have been mixed, with some studies reporting small bilingual advantages and others finding no advantage (Bialystok et al., 2005; Costa et al., 2009;
Garbin et al., 2010; Hilchey and Klein, 2011; Abutalebi et al., 2012). Our behavioral task-switching results thus extend previous findings from inhibitory control paradigms, suggesting that the effects of lifelong bilingualism on task switching are larger in older adults than young adults.

We tested the possibilities that cognitive control advantages in bilingual older adults may reflect maintained neural efficiency or increased neural compensation. Aging has been linked with decreases in neural efficiency, as evidenced by activation increases in primary task-related regions accompanied by poorer performance on difficult cognitive tasks (Rypma and D'Esposito, 2000; Park et al., 2001; Colcombe et al., 2005; Zarahn et al., 2007; Stern, 2009), and neural compensation, typically defined as activation increases outside the primary task-related network accompanied by better task performance (Grady et al., 1994; Cabeza et al., 1997; Reuter-Lorenz et al., 1999). In the present study, older adults displayed activation increases in multiple task-relevant frontal regions and poorer switching performance compared with younger adults, suggesting age-related declines in neural efficiency for task switching.

However, lifelong bilingualism offset several of these age-related declines in neural efficiency for task switching. Specifically, like the younger adult groups, bilingual older adults outperformed their monolingual peers despite requiring less activation in three key frontal hubs of the task-switching network: left DLPFC, left VLPFC, and ACC. Importantly, higher BOLD response in each of these regions was directly correlated with poorer switching performance in the older adult groups. This finding is consistent with previous results linking higher BOLD response in prefrontal cortex with slower, more effortful processing on complex tasks (Kosslyn et al., 1996; Rypma and D’Esposito, 2000; Rypma et al., 2002). Our novel results from a mediation analysis showed that the reduced BOLD response in bilingual older adults across all three ROIs accounted for $82 \%$ of the variance in their RT advantage. This suggests that neural efficiency may represent a core underlying mechanism of the bilingual task-switching advantage in aging.

Based on our findings, it is reasonable to consider why lifelong bilingualism specifically affected the neural efficiency in the left prefrontal and ACC regions as opposed to other regions of the task-switching network such as right prefrontal cortex. One possible answer can be gleaned from the language-switching litera- 

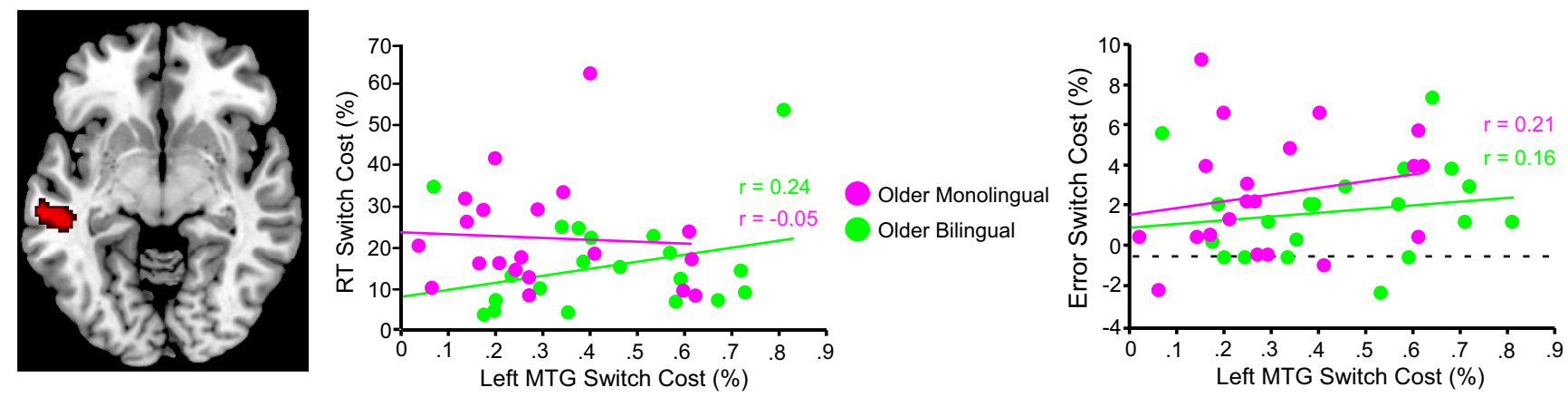

Figure 5. Effect of language group on switching activation. Voxelwise contrast indicated increased activation in lifelong bilinguals compared with monolinguals in left MTG. Regression plots show the nonsignificant correlations between neural switch costs and proportional RT switch costs or error switch costs in the left MTG. Each circle represents one of the 20 participants in each older adult (monolingual or bilingual) group.

ture. This literature indicates that there is significant overlap between the left PFC and ACC regions used during perceptual switching and language switching (Abutalebi and Green, 2007; Guo et al., 2011). The overlap in the neural correlates of language switching and perceptual switching regions provides a plausible mechanism for bilingual advantages in executive control. Specifically, it may be the case that the bilingual requirement to switch between languages on a daily basis serves to tune the efficiency of language-switching regions (left prefrontal cortex and ACC), and that over time the increased efficiency of these regions comes to benefit even nonlinguistic, perceptual switching (Abutalebi et al., 2012).

We also explored the possibility that increased neural efficiency in older adult bilinguals may result from better structural brain integrity. However, results from the VBM comparison indicated no significant regional volumetric differences between older adult bilinguals and monolinguals. This is not to say that bilingualism cannot be associated with variations in brain structure, as previous results have reported both cerebral atrophy (Schweizer et al., 2012) and higher WM integrity (Luk et al., 2011) in older adult bilinguals compared with their monolingual peers. Our results do, however, suggest a functional basis of bilingual cognitive control advantages in older adults that cannot be explained by macroscopic differences in brain volume. Future research will be required to determine whether bilingual behavioral advantages and improved neural efficiency observed here are associated with differences in WM microstructure.

We found no evidence that bilingual task-switching advantages in aging are based upon neural compensation. Bilingualism was associated with increased task-switching activation in MTG, but this increase manifested as a main effect of bilingualism (present in both younger and older adult bilinguals) rather than an age by language group interaction. Moreover, left MTG activation was not correlated with task-switching performance in bilingual older adults. Left MTG activation has, however, been strongly linked with semantic processing (Vandenberghe et al., 1996; Gold and Buckner, 2002). In particular, given that left MTG contributes to automatic lexical-semantic processes (Gold et al., 2006), its increased activation in bilinguals may reflect automatic activation of corresponding lexical entries (possibly related to cue words) in the nonrelevant language. In any case, the observed increase in left MTG activation may be an epiphenomenon of bilingualism as it was incidental to task-switching performance in the present study.

Together, our results suggest that benefits of lifelong bilingualism are based upon a shift in cognitive control processing from effortful to more automatic. The notion that a shift from strategic to automatic processing can result in performance differences is not new (Hasher and Zacks, 1979). It is also well established that repeated performance of higher cognitive tasks results in faster RT and reduced brain activation, particularly in frontal cortex (Demb et al., 1995; Qin et al., 2003; Gold et al., 2005). Of particular relevance to the present results are findings from two studies exploring the effects of cognitive or cardiovascular training on cognitive control processing and brain activations in aging (Colcombe et al., 2004; Erickson et al., 2007). These training regimens improved cognitive control performance and reduced brain activation in some regions that older adults over-recruited compared with younger adults before training. Lifelong bilingualism may represent a naturalistic analog of such training interventions, serving to maintain cognitive control processes in aging and thus reducing the need for age-related over-recruitment.

The present study has several caveats that highlight the need for future work in this field. First, the present study did not address the influence of age of acquisition on bilingual advantages. Based on the present and previous results, future longitudinal research should determine whether intensive language immersion can improve cognitive control performance in monolingual older adults. Second, additional research will be required to more precisely characterize the nature of functional efficiency advantages we observed. For example, future research should consider blood flow measures using arterial spin labeling and spectroscopy measures of metabolite ratios reflecting various molecular and cellular processes. Finally, our null findings concerning compensatory activation do not rule out a more subtle contribution of this mechanism to bilingual cognitive control advantages. Future studies should continue to explore this possibility, as well as other functional anatomic variations that can be directly linked with bilingual cognitive control advantages.

In conclusion, our results demonstrate that lifelong bilingualism attenuates age-related declines in perceptual task switching. Our results suggest that the bilingual advantage in aging is at least in part the result of more efficient use of neural resources. Specifically, bilingual older adults outperformed their monolingual peers despite requiring less activation in primary task-switching regions in which higher response was directly correlated with slower switching. It appears that the lifelong bilingual experience of continuously switching between two languages strengthens general-purpose executive control systems, maintaining their neural efficiency in aging. Lifelong bilingualism thus confers not only social and eco- 
nomic advantages, but benefits the functioning of the aging brain.

\section{References}

Abutalebi J, Green DW (2007) Bilingual language production: the neurocognition of language representation and control. J Neurolinguistics 20: 242-275. CrossRef

Abutalebi J, Della Rosa PA, Green DW, Hernandez M, Scifo P, Keim R, Cappa SF, Costa A (2012) Bilingualism tunes the anterior cingulate cortex for conflict monitoring. Cereb Cortex 22:2076-2086. CrossRef Medline

Ashburner J, Friston KJ (2005) Unified segmentation. Neuroimage 26:839851. CrossRef Medline

Bialystok E, Craik FIM (2010) Cognitive and linguisitc processing in the bilingual mind. Curr Dir Psychol Sci 19:19-23. CrossRef

Bialystok E, Craik FI, Grady C, Chau W, Ishii R, Gunji A, Pantev C (2005) Effect of bilingualism on cognitive control in the Simon task: evidence from MEG. Neuroimage 24:40-49. CrossRef Medline

Bialystok E, Craik FI, Ryan J (2006) Executive control in a modified antisaccade task: effects of aging and bilingualism. J Exp Psychol Learn Mem Cogn 32:1341-1354. CrossRef Medline

Bialystok E, Craik FI, Freedman M (2007) Bilingualism as a protection against the onset of symptoms of dementia. Neuropsychologia 45:459464. CrossRef Medline

Brass M, von Cramon DY (2002) The role of the frontal cortex in task preparation. Cereb Cortex 12:908-914. CrossRef Medline

Cabeza R, Grady CL, Nyberg L, McIntosh AR, Tulving E, Kapur S, Jennings JM, Houle S, Craik FI (1997) Age-related differences in neural activity during memory encoding and retrieval: a positron emission tomography study. J Neurosci 17:391-400. Medline

Cattell RB, Cattell AKS (1960) Handbook for the individual or group culture fair intelligence test. Savoy, IL: Institute for Personality and Ability Testing.

Colcombe SJ, Kramer AF, Erickson KI, Scalf P, McAuley E, Cohen NJ, Webb A, Jerome GJ, Marquez DX, Elavsky S (2004) Cardiovascular fitness, cortical plasticity, and aging. Proc Natl Acad Sci U S A 101: 3316-3321. CrossRef Medline

Colcombe SJ, Kramer AF, Erickson KI, Scalf P (2005) The implications of cortical recruitment and brain morphology for individual differences in inhibitory function in aging humans. Psychol Aging 20:363375. CrossRef Medline

Costa A, Hernández M, Sebastián-Gallés N (2008) Bilingualism aids conflict resolution: evidence from the ANT task. Cognition 106:59-86. CrossRef Medline

Costa A, Hernéndez M, Costa-Faidella J, Sebastián-Gallés N (2009) On the bilingual advantage in conflict processing: now you see it, now you don't. Cognition 113:135-149. CrossRef Medline

Demb JB, Desmond JE, Wagner AD, Vaidya CJ, Glover GH, Gabrieli JD (1995) Semantic encoding and retrieval in the left inferior prefrontal cortex: a functional MRI study of task difficulty and process specificity. J Neurosci 15:5870-5878. Medline

DiGirolamo GJ, Kramer AF, Barad V, Cepeda NJ, Weissman DH, Milham MP, Wszalek TM, Cohen NJ, Banich MT, Webb A, Belopolsky AV, McAuley E (2001) General and task-specific frontal lobe recruitment in older adults during executive processes: a fMRI investigation of taskswitching. Neuroreport 12:2065-2071. CrossRef Medline

Dove A, Pollmann S, Schubert T, Wiggins CJ, von Cramon DY (2000) Prefrontal cortex activation in task switching: an event-related fMRI study. Brain Res Cogn Brain Res 9:103-109. CrossRef Medline

Dunn LM, Dunn, E.S. (1997) The Peabody Picture Vocabulary Test-III. Circle Pines, MN: American Guidance Service.

Erickson KI, Colcombe SJ, Wadhwa R, Bherer L, Peterson MS, Scalf PE, Kim JS, Alvarado M, Kramer AF (2007) Training-induced functional activation changes in dual-task processing: an FMRI study. Cereb Cortex 17: 192-204. Medline

Francis WS (1999) Analogical transfer of problem solutions within and between languages in Spanish-English bilinguals. J Mem Lang 40:301-329. CrossRef

Friston KJ, Penny WD, Glaser DE (2005) Conjunction revisited. Neuroimage 25:661-667. CrossRef Medline

Garbin G, Sanjuan A, Forn C, Bustamante JC, Rodriguez-Pujadas A, Belloch V, Hernandez M, Costa A, Avila C (2010) Bridging language and atten- tion: brain basis of the impact of bilingualism on cognitive control. Neuroimage 53:1272-1278. CrossRef Medline

Gold BT, Buckner RL (2002) Common prefrontal regions coactivate with dissociable posterior regions during controlled semantic and phonological tasks. Neuron 35:803-812. CrossRef Medline

Gold BT, Balota DA, Kirchhoff BA, Buckner RL (2005) Common and dissociable activation patterns associated with controlled semantic and phonological processing: evidence from FMRI adaptation. Cereb Cortex 15: 1438-1450. Medline

Gold BT, Balota DA, Jones SJ, Powell DK, Smith CD, Andersen AH (2006) Dissociation of automatic and strategic lexical-semantics: functional magnetic resonance imaging evidence for differing roles of multiple frontotemporal regions. J Neurosci 26:6523-6532. CrossRef Medline

Gold BT, Powell DK, Xuan L, Jicha GA, Smith CD (2010) Age-related slowing of task switching is associated with decreased integrity of frontoparietal white matter. Neurobiol Aging 31:512-522. CrossRef Medline

Grady CL, Maisog JM, Horwitz B, Ungerleider LG, Mentis MJ, Salerno JA, Pietrini P, Wagner E, Haxby JV (1994) Age-related changes in cortical blood flow activation during visual processing of faces and location. J Neurosci 14:1450-1462. Medline

Green DW (1998) Mental control of the bilingual lexico-semantic system. Bilingualism 1:67-81. CrossRef

Guo T, Liu H, Misra M, Kroll JF (2011) Local and global inhibition in bilingual word production: fMRI evidence from Chinese-English bilinguals. Neuroimage 56:2300-2309. CrossRef Medline

Hasher L, Zacks RT (1979) Automatic and effortful processes in memory. J Exp Psychol Gen 108:356-388. CrossRef

Hilchey MD, Klein RM (2011) Are there bilingual advantages on nonlinguistic interference tasks? Implications for the plasticity of executive control processes. Psychon Bull Rev 18:625-658. CrossRef Medline

Hollingshead AB (1958) Social class and mental illness: a community study. New York: Wiley.

Jimura K, Braver TS (2010) Age-related shifts in brain activity dynamics during task switching. Cereb Cortex 20:1420-1431. CrossRef Medline

Kim C, Johnson NF, Cilles SE, Gold BT (2011) Common and distinct mechanisms of cognitive flexibility in prefrontal cortex. J Neurosci 31:47714779. CrossRef Medline

Kim C, Cilles SE, Johnson NF, Gold BT (2012) Domain general and domain preferential brain regions associated with different types of task switching: a meta-analysis. Hum Brain Mapp 33:130-142. CrossRef Medline

Kosslyn SM, Thompson WL, Kim IJ, Rauch SL, Alpert NM (1996) Individual differences in cerebral blood flow in area 17 predict the time to evaluate visualized letters. J Cogn Neurosci 8:78-82. CrossRef

Kramer AF, Hahn S, Gopher D (1999) Task coordination and aging: explorations of executive control processes in the task switching paradigm. Acta Psychol 101:339-378. CrossRef

Kray J, Lindenberger U (2000) Adult age differences in task switching. Psychol Aging 15:126-147. CrossRef Medline

Luk G, Bialystok E, Craik FI, Grady CL (2011) Lifelong bilingualism maintains white matter integrity in older adults. J Neurosci 31:1680816813. CrossRef Medline

Madden DJ, Costello MC, Dennis NA, Davis SW, Shepler AM, Spaniol J, Bucur B, Cabeza R (2010) Adult age differences in functional connectivity during executive control. Neuroimage 52:643-657. CrossRef Medline

Meiran N, Gotler A, Perlman A (2001) Old age is associated with a pattern of relatively intact and relatively impaired task-set switching abilities. J Gerontol B Psychol Sci Soc Sci 56:P88-P102. CrossRef Medline

Miller EK, Cohen JD (2001) An integrative theory of prefrontal cortex function. Annu Rev Neurosci 24:167-202. CrossRef Medline

Park DC, Polk TA, Mikels JA, Taylor SF, Marshuetz C (2001) Cerebral aging: integration of brain and behavioral models of cognitive function. Dialogues Clin Neurosci 3:151-165. Medline

Qin Y, Sohn MH, Anderson JR, Stenger VA, Fissell K, Goode A, Carter CS (2003) Predicting the practice effects on the blood oxygenation leveldependent (BOLD) function of $\mathrm{fMRI}$ in a symbolic manipulation task. Proc Natl Acad Sci U S A 100:4951-4956. CrossRef Medline

Reuter-Lorenz PA, Stanczak L, Miller AC (1999) Neural recruitment and cognitive aging: two hemispheres are better than one especially as you age. Psychol Sci 10:494-500. CrossRef

Reynolds JR, Donaldson DI, Wagner AD, Braver TS (2004) Item- and tasklevel processes in the left inferior prefrontal cortex: positive and negative correlates of encoding. Neuroimage 21:1472-1483. CrossRef Medline 
Rypma B, D’Esposito M (2000) Isolating the neural mechanisms of agerelated changes in human working memory. Nat Neurosci 3:509-515. CrossRef Medline

Rypma B, Berger JS, D'Esposito M (2002) The influence of workingmemory demand and subject performance on prefrontal cortical activity. J Cogn Neurosci 14:721-731. CrossRef Medline

Salthouse TA (1993) Speed mediation of adult age differences in cognition. Dev Psychol 29:722-738. CrossRef

Schweizer TA, Ware J, Fischer CE, Craik FI, Bialystok E (2012) Bilingualism as a contributor to cognitive reserve: evidence from brain atrophy in Alzheimer's disease. Cortex 48:991-996. CrossRef Medline

Smith MC (1997) How do bilinguals access lexical information?, Tutorials in bilingualism: psycholinguistic perspectives edition. Mahwah, NJ: Lawrence Erlbaum.
Stern Y (2009) Cognitive reserve. Neuropsychologia 47:2015-2028. CrossRef Medline

Vandenberghe R, Price C, Wise R, Josephs O, Frackowiak RS (1996) Functional anatomy of a common semantic system for words and pictures. Nature 383:254-256. CrossRef Medline

Wechsler DS (1997) Wechsler Adult Intelligence Scale-3rd Edition (WAIS-3) San Antonio, TX: Harcourt Assessment.

West RL (1996) An application of prefrontal cortex function theory to cognitive aging. Psychol Bull 120:272-292. CrossRef Medline

Zarahn E, Rakitin B, Abela D, Flynn J, Stern Y (2007) Age-related changes in brain activation during a delayed item recognition task. Neurobiol Aging 28:784-798. CrossRef Medline 